\title{
Advance directives: obstacles in preparing for the worst
}

$\mathrm{C}$ onfusion and cultural taboos continue to pose barriers for many Canadians in documenting how they want to be treated in the event they become incapable of making health care choices.

Excluding Nunavut, all provinces and territories in Canada currently provide a legal framework for a person to write instructions about the care they would want (or not want) to receive should they lose their capacity to give informed consent.

These "advance directives" have been formally recognized in pockets of the country for almost two decades. But they've yet to become a routine part of health care planning in Canada, in part because of a lack of standardization, as well as the reluctance of patients and health care providers to talk about death and disability.

"It's always a challenge when you have a number of different styles of document on your hands. How do you decipher what they all mean?" says Brenda Lee Doyle, provincial director of the Alberta Office of the Public Guardian.

Across the country, advance directives are generally used for two purposes: to appoint a substitute health care decision maker and to set out treatment preferences that must be followed by health care providers where applicable, reasonable and legal.

But because most provinces and territories don't place many restrictions on who can draft directives, and how, the final look of the document can vary widely from person to person and province to province. In some jurisdictions, a person has to be older than 16 years of age to write a directive; in others, older than 19. Some jurisdictions require that the document be signed and witnessed. Some don't provide for instructional directives.

"It's amazing how different the terminology is between provinces," says Dr. Romayne Gallagher, a clinical professor in the division of palliative care

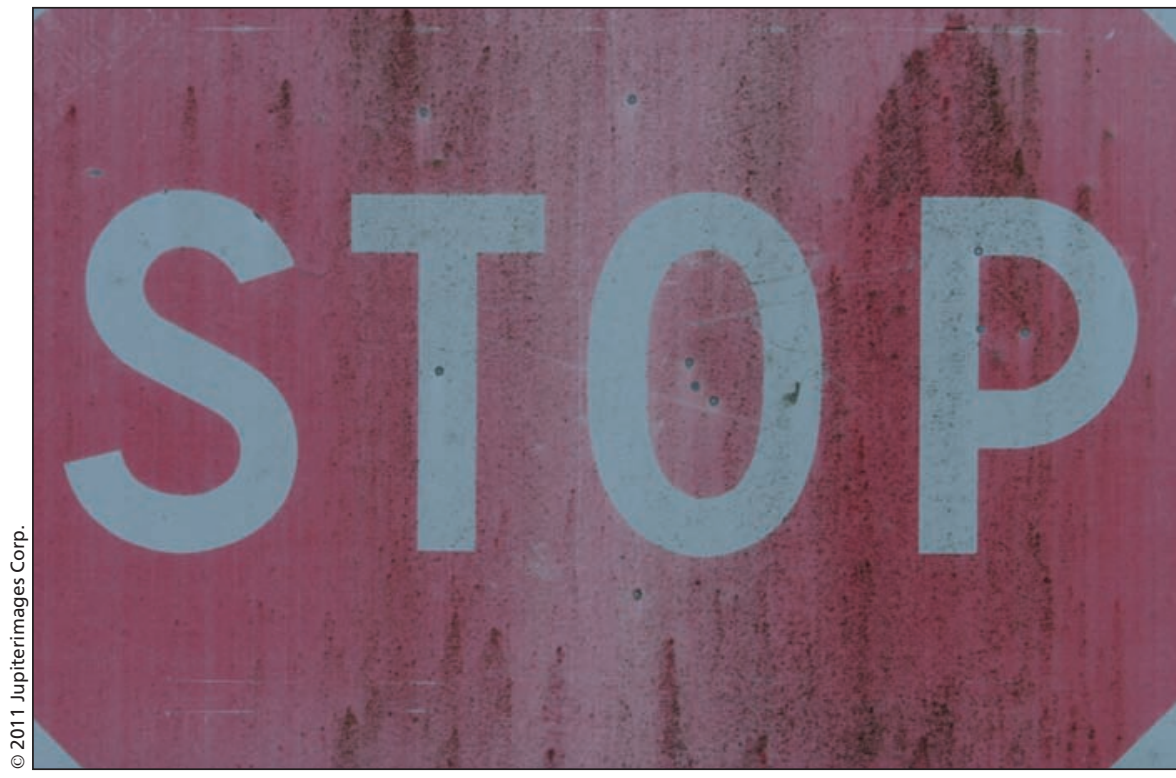

Canadians face conflicting advice on how general or specific their instructions should be about the care they want or, in many cases, do not want to receive should they lose their capacity to give informed consent.

at the University of British Columbia, in Vancouver.

The Yukon, Newfoundland and Labrador, Prince Edward Island, Manitoba and Saskatchewan all use some variant of "advance directive" or "health care directive" to describe the documents, while Alberta, Nova Scotia and the Northwest Territories prefer to call it a "personal directive." Residents of Ontario and New Brunswick can draft a "power of attorney for personal care," while residents of Quebec and British Columbia use "mandates" and "representation agreements," respectively (www.hc-sc .gc.ca/hcs-sss/pubs/palliat/2006-proj-glos /2006-proj-glos-4-eng.php).

A person can only appoint a "substitute decision maker" in Newfoundland and Labrador. Elsewhere, they're called "agents" (Alberta and NWT), "attorneys for personal care" (Ontario and New Brunswick), "guardians" (Nova Scotia), "mandataries" (Quebec), "proxies" (PEI, Yukon, Manitoba and Saskatchewan) or "representatives" (BC).

Even within the provinces, lawyers have drafted documents so riddled with clauses and unique phrasing that they're "unrecognizable" as advance directives to health care providers, Doyle says.

Alberta became the only province to offer a standardized advance directive form in 2008, following a legislative review.

"What we heard from the public was that people didn't know what to include or what to consider when writing an advance directive, despite the educational materials that were available," says Doyle. "In the two years since we've begun offering the standard form, we've seen the number of Albertans with advance directives jump from 100000 to roughly 400000 , and that's just people that registered their directives."

Canadians also face conflicting advice on how general or specific their instructions should be, according to a Canadian Hospice and Palliative Care Association working document (www .chpca.net/projects/advance_care_plan ning/acp_environmental_scan_sept_9 _09.pdf).

The association's Advance Care Planning: Environmental Scan suggests a divide in the health and legal sectors over 
whether an advance directive should provide detailed, disease and procedurespecific instructions "without reference to substitute decision-makers," or whether it should be restricted to expressions of values that could be applied contextually.

There are pitfalls to both approaches, says Leah Hutt, a research associate with the Health Law Institute at Dalhousie University in Halifax, NS. On the one hand, there is a risk of being too vague and giving instructions that could mean any number of things, such as: Do not use "heroic" measures. On the other hand, too-detailed instructions leave no flexibility for changes in circumstance, medical knowledge and technology, she says.

Gallagher says that "someone might say, 'If I'm really ill, I don't want any antibiotics'. We would honour that, but there are times we'd want to give antibiotics to someone with a severe infection, not to prolong life but just to make them more comfortable. And ultimately, no one knows exactly how they're going to die."

Some of the confusion around advance directives could be cleared up if patients discussed their plans with health care providers, but many people find the subject difficult to broach, says Dr. Doris Barwich, medical director of Fraser Health Hospice Palliative Care in BC. "People get sick, they get over- whelmed and planning takes a second place to just coping. They have too little time, they don't know what to ask the doctor, and surely if it was important, they think, the doctor would bring it up themselves."

Even when a person is healthy, disability and dying remain taboos, says Gallagher. "Some people believe talking about something can make it more likely to happen, others feel we shouldn't plan because it's an affront to God. Who are they to plan when God will make the call when their time is up?"

But patients aren't alone in being uncomfortable with advance care planning conversations. "I still run across physicians who say they don't want to talk about advance care planning with patients because they don't want to take away their hope," says Gallagher. "But people tend to take the lead from their health care provider, so your comfort level will really determine the patient's comfort level."

In fact, many consumers are "eager" to discuss advance care plans if given the opportunity in a supportive environment, according to a 2006 Health Canada report (www.hc-sc.gc.ca/hcs-sss /pubs/palliat/2006-proj-glos/2006-proj -glos-4-eng.php).

And initiating the conversation isn't as difficult or as time-consuming as some physicians believe, Gallagher says.

"Patients will give clues when they want to talk, like saying at a follow up after a visit to the hospital that they don't want to go back there any time soon. A doctor can let that comment slide or can take five, maybe 10 minutes to ask what the patient would want to do in future," she says. "I've been in situations where doctors said they wouldn't dare approach a patient about end of life for fear of freaking her out, and it turned out the patient not only had an advance directive but had appointed a substitute decision maker. She was clear on what she wanted, but just needed to be asked."

For now, the onus is on the patient to indicate if they have an advance directive, but trust remains a hurdle, even for those who have made plans.

"People worry about bringing it up because they don't want to be treated differently when they're still capable, or be seen as through they've given up," says Gallagher. "A lot of the language around this issue is 'I' $m$ still fighting to stay alive,' so we need to make patients comfortable to hope for the best and plan for the worst." Lauren Vogel, CMAJ

CMAJ 2011.DOI:10.1503/cmaj.109-3743 